\title{
Biotherapy Effect of Shenfuweikang Herbs on Gastric Carcinoma
}

\author{
Xiao-ping WANG ${ }^{1,{ }^{*}}$, Huan-ping $\operatorname{LIN}^{1}$, Qiao-xia WANG ${ }^{2}$, Bing $X U^{1}$, Yi \\ $\mathrm{LI}^{1}$, Bao-ning $\mathrm{QI}^{1}, \mathrm{Xu}-\mathrm{xu}$ WEI ${ }^{1}$ and Peng-fei ZHANG ${ }^{3}$ \\ ${ }^{1}$ Department of Pathology, Shaanxi University of Chinese Medicine, Xianyang, China \\ ${ }^{2}$ Xi'an Central Hospital, School of Medicine, Xi'an Jiaotong University, Xi'an, China \\ ${ }^{3}$ The First Clinical Hospital, School of Medicine, Xi'an Jiaotong University, Xi'an, China
}

${ }^{*}$ Corresponding author

Keywords: Biotherapy, Shenfuweikang, Cytotoxicity, Immunity, Gastric cancer.

\begin{abstract}
To study the biotherapy effect of Shenfuweikang herbs in treatment of gastric cancer, Kunming mice were grafted with a mouse gastric adenocarcinoma cell line MFC. Mice received different doses of Shefuweikang herbs after grafting. Tumor size was periodically measured and tumor weight was determined after the animals sacrificed. Apoptotic indices (AI) were examined by TUNEL assay and flow cytometric analysis. Serum cytokines IFN- $\gamma$ and granzyme B were detected by ELISA. The anti-tumor effect was determined by the cytotoxic T-lymphocyte (CTL) assays. Our results demonstrated that Shefuweikang herbs could induce apoptosis and inhibit the growth of gastric cancer by activating the CTLs and eliciting the secretion of cytokines, IFN- $\gamma$ and granzyme B. Our study suggests that Shefuweikang herbs inhibit the proliferation of gastric carcinoma by inducing the apoptosis of tumor cells and activating the effects of immune cells, which may lay a better basis for further study on gastric cancer biotherapy.
\end{abstract}

\section{Introduction}

In clinic studies, Chinese Shenfuweikang herbs had been found to have effect on pre-malignant lesion, especially on gastric diseases [1,2]. The Shenfuweikang Decoction might inhibit gastric carcinoma cell proliferation and cause tumor cell death. Apoptosis plays a crucial role in the proliferation and turnover of cells in various tumors. It has been clear that its extent is often enhanced in tumor by many anticancer drugs, such as cytotoxic drugs, hormone, or some Chinese herbal medicine [3,4]. Researches indicated that Chinese herbs could enhance apoptosis of human gastric cancer grafted in mice [5,6].

In the present study, we investigated whether the Shenfuweikang herbs could induce the effects of the immune cells against gastric cancer grafted onto mice, further confirming the anti-tumor mechanism of the Chinese Shenfuweikang herbs.

\section{Material and Methods}

\section{Mice and Tumor Cell Lines}

Fifty six- to eight-week-old female Kunming mice were purchased from the Experimental Animal Center at Fourth Military Medical University. All animals were maintained under specific-pathogen-free conditions, and all procedures were performed according to approved protocols and in accordance with recommendations 
for the proper care of laboratory animals. The investigation was approved by the Ethics Committee on animal Study at Shaanxi University of Chinese Medicine (2004-4B).

\section{Drugs}

The Shenfuweikang decoction consists of Codonopsis pilosula (Franch) Nannf., Poria $\operatorname{cocos}$ (Schw.) Wolf, Atractylodes macrocephala koidz, Glycyrrhiza uralensis Fisch. The concentration of the Shenfuweikang decoction was $240 \mathrm{~g} / \mathrm{L}$.

\section{Administration}

After grafting the mice were randomly divided into 4 groups, one control and the other three experimental groups assigned to receive the Shenfuweikang Decoction. Each animal in the three experimental groups was given $2.0 \mathrm{~mL}, 1.0 \mathrm{~mL}$ and $0.5 \mathrm{~mL}$ of the Shenfuweikang Decoction by gastric perfusion every day over a 60-day period beginning at 1 st day after grafting. The control animals received normal saline according to the same schedule. Animals were killed 61 days after being grafted.

\section{Detection of Apoptosis}

For detection of apoptotic cells, apoptotic indices were examined by the terminal deoxynucleotidyl transferase-mediated deoxyuridine triphosphate fluorescence nick end labeling (TUNEL) method and flow cytometry analysis. (1) TUNEL: In situ cell death detection Kit POD (Roche Applied Science, Indianapolis, USA) was used to detect the apoptotic cell. The procedures were referred to the kit protocol. The positive cells were identified, counted and analyzed under the light microscope. Non-necrotic zone was selected in the tissue section and images were sent to computer by AEC camera (ZEISS, Jena, Germany). 10 image at least 1000 cells were selected on the screen, positive ratio analyzed by KS400 Video Image Digital Analysis System (ZEISS, Jena, Germany). (2) Flow cytometry analysis: Propidium iodide (PI) staining was used for flow cytometry detection of apoptosis. $10^{6}$ cells from each of the sample were treated with RNase and stained with PI. The apoptotic cells having DNA strand breaks that had been labeled were measured on a flow cytometer (FACSCalibur, Becton Dickinson, USA). The data from $10^{6}$ cells/sample were collected, stored, and analyzed using CELLQUEST (Becton Dickinson USA) and ModFIT LT for mac V1.01 software (Becton Dickinson, USA).

\section{IFN- $\gamma$ and Granzyme B ELISA Assay}

The ELISA was used to measure the cytokine IFN- $\gamma$ and granzyme B in serum collected from above mice according to manufacturer's instruction. The OD values were obtained using an ELISA Reader System.

\section{Cytotoxic T-lymphocyte (CTL) Assays}

Kunming mice were administrated as described above. The 61 day, $2.5 \times 10^{7}$ splenocytes were collected from the different mice groups and cultured with $10 \mathrm{units} / \mathrm{ml}$ of mouse interleukin (IL)-2 in RPMI 1640 supplemented with $10 \%$ FCS at $37{ }^{\circ} \mathrm{C}$ in $5 \% \mathrm{CO}_{2}$. After 5 days of stimulation, the viable splenocytes were recovered and used as effector cells, and the MFC cells were used as target cells. The Non-Radioactive Cytotoxicity Lactate Dehydrogenase (LDH) release assay Kit (Promega, 249 USA) was performed to measure the effector cells against MFC tumor cells in the ratios of 10:1, 20:1 and 40:1, according to the manufacturer's protocol. Specific lysis was calculated according to the formula: percent specific lysis $=[($ experimental release value - effector spontaneous release value - target spontaneous release value)/(target maximum release 
value - target spontaneous release value) $] \times 100$. Results shown are representative of experiments repeated three times.

\section{In Vivo Tumor Therapeutic Experiments}

To confirm whether Shenfuweikang herbs inhibited the growth of established tumors, one control and the other three experimental groups were assigned to receive the Shenfuweikang Decoction. Each animal in the three experimental groups was given $2.0 \mathrm{~mL}, 1.0 \mathrm{~mL}$ and $0.5 \mathrm{~mL}$ of the Shenfuweikang Decoction by gastric perfusion every day over a 60-day period beginning at 1 st day after grafting. The control animals received normal saline according to the same schedule. $5 \times 10^{6}$ MFC tumor cells were washed after enzymatic digestion and resuspended in $0.2 \mathrm{ml}$ of PBS per animal, then injected s.c. into the left flank. Tumor size was measured in two dimensions with calipers every 3 days one week after tumor inoculation. Tumor volume was calculated using the formula: $\mathrm{V}=\left(\mathrm{a}^{2} \mathrm{~b}\right) / 2$. The tumor tissues were made into sections and stained with Hematoxylin and Eosin. The morphological changes of tumor were observed and analyzed under microscope.

\section{Statistical Analysis}

All data expressed as means \pm S.D. The Student's t test was performed to analyze the significance of differences in different groups of mice. $P<0.05$ was considered statistically significant.

\section{Results}

\section{Inhibition of Tumor Growth by Shenfuweikang Herbs}

Compared with the control group, tumor growth (size and weight) was significantly inhibited by treatment with the Shenfuweikang decoction $(\mathrm{P}<0.05$, Table 1$)$. The results showed that the higher the concentration of Shenfuweikang herbs, the less the tumor weight and size. There was a significant difference between the Chinese herbs and control group. The morphological changes of tumor were showed as Figure 1. Compared with the control group, the gastric adenocarcimoma glands were less and smaller in Shenfuweikang decoction treated group.

Table 1. Shenfuweikang herbs inhibited the tumor growth of gastric cancer $(\mathrm{x} \pm \mathrm{s})$

\begin{tabular}{|c|c|c|}
\hline Treatment & Tumor weight $(\mathrm{g})$ & Tumor size $\left(\mathrm{mm}^{3}\right)$ \\
\hline High-dose Shenfuweikang Decoction & $0.48 \pm 0.23^{\mathrm{a}}$ & $262.74 \pm 41.56^{\mathrm{a}}$ \\
\hline Middle-dose Shenfuweikang Decoction & $0.62 \pm 0.27^{\mathrm{b}}$ & $335.43 \pm 34.25^{\mathrm{b}}$ \\
\hline Low-dose Shenfuweikang Decoction & $0.78 \pm 0.24^{\mathrm{c}}$ & $453.42 \pm 26.68^{\mathrm{c}}$ \\
\hline Saline & $1.92 \pm 0.25$ & $587.32 \pm 73.28$ \\
\hline
\end{tabular}

${ }^{\mathrm{a}} \mathrm{P}<0.05,{ }^{\mathrm{b}} \mathrm{P}<0.05,{ }^{\mathrm{c}} \mathrm{P}<0.05$ vs control group. 


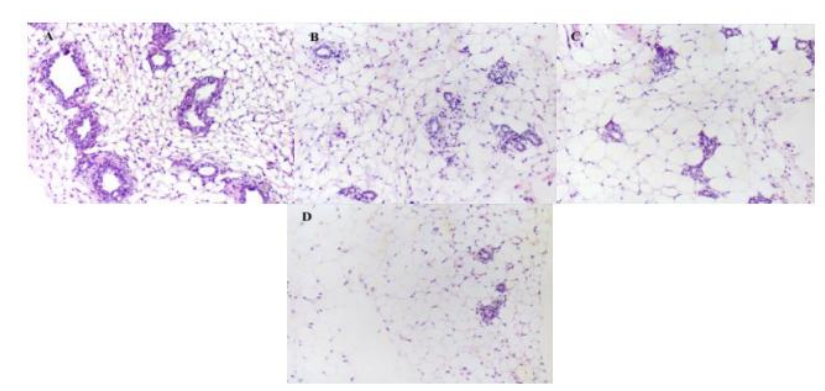

Figure 1. The morphological changes of gastric adenocarcimoma in different groups, $\times 200$. A.Control group, B. Low-dose group, C. Middle-dose group, D. High-dose group.

\section{Induction of Tumor Cell Apoptosis by Shenfuweikang Herbs}

Apoptotic index (AI) in mice loaded with gastric cancer cells was significantly elevated to $18.53 \pm 2.36 \%$ by TUNEL method and $17.85 \pm 5.43 \%$ FACScan in the Shenfuweikang decoction treatment group, compared with the controls (TUNEL: $3.96 \pm 1.53 \%, \mathrm{P}<0.05$; FACScan: $5.04 \pm 2.15 \%, \mathrm{P}<0.05)$. But there was no significant difference between low-dose Shenfuweikang decoction treated group and control group by using either TUNEL method or flow cytometry analysis (Table 2).

Table 2. Shenfuweikang herbs induced apoptosis on gastric cancer cells $(\mathrm{x} \pm \mathrm{s})$

\begin{tabular}{|c|c|c|}
\hline \multirow{2}{*}{ Treatment } & \multicolumn{2}{|c|}{ Apoptotic index $(\mathrm{AI})(\%)$} \\
\cline { 2 - 3 } & TUNEL & FACScan \\
\hline High-dose Shenfuweikang Decoction & $18.53 \pm 2.36^{\mathrm{a}}$ & $17.85 \pm 5.43^{\mathrm{a}}$ \\
\hline Middle-dose Shenfuweikang Decoction & $11.24 \pm 5.34^{\mathrm{b}}$ & $10.45 \pm 4.37^{\mathrm{b}}$ \\
\hline Low-dose Shenfuweikang Decoction & $4.06 \pm 1.57^{\mathrm{c}}$ & $5.13 \pm 2.28^{\mathrm{c}}$ \\
\hline Control & $3.96 \pm 1.53$ & $5.04 \pm 2.15$ \\
\hline
\end{tabular}

${ }^{\mathrm{a}} \mathrm{P}<0.05,{ }^{\mathrm{b}} \mathrm{P}<0.05,{ }^{\mathrm{c}} \mathrm{P}>0.05$ vs control group.

Shenfuweikang Herbs Induced the Up-regulation of IFN- $\gamma$ and Granzyme B in Vivo

The concentrations of IFN- $\gamma$ and granzyme B in serum from the experimental mice were much more higher compared with those from mice treated with $\mathrm{PBS}(\mathrm{P}<0.05$, Table 3$)$. The results indicated that Shenfuweikang herbs could induce significant immune T cells response compared with the control group.

Table 3. Shenfuweikang herbs induced the up-regulation of IFN- $\gamma$ and granzyme $B$ in vivo ( \pm s)

\begin{tabular}{|c|c|c|}
\hline Treatment & $\mathrm{IFN}-\gamma(\mu \mathrm{g} / \mathrm{ml})$ & Granzyme B $(\mu \mathrm{g} / \mathrm{ml})$ \\
\hline High-dose Shenfuweikang Decoction & $388.25 \pm 16.47^{\mathrm{a}}$ & $314.57 \pm 12.93^{\mathrm{a}}$ \\
\hline Middle-dose Shenfuweikang Decoction & $279.63 \pm 11.32^{\mathrm{b}}$ & $253.42 \pm 8.62^{b}$ \\
\hline Low-dose Shenfuweikang Decoction & $158.724 \pm 9.28^{\mathrm{c}}$ & $134.66 \pm 7.72^{\mathrm{c}}$ \\
\hline Saline & $6.38 \pm 1.29$ & $5.59 \pm 0.45$ \\
\hline
\end{tabular}

\section{Shenfuweikang Herbs Elicited Specific CTLs Response}

Cytotoxicity assay showed that splenocytes cells from mice treated with Shenfuweikang herbs exhibited higher cytolytic effects on MFC target cells than those from mice vaccinated with PBS $(\mathrm{P}<0.01)$. In contrast, splenocytes from the PBS control showed a weaker ability of target cells lysis. Our results indicated that Shenfuweikang herbs was an inducer for specific immune cell activity. 


\section{Discussion}

Gastric carcinoma is one of the most common malignant gastrointestinal carcinoma in the world. At present gastric carcinoma is still detected later in most patients throughout the world, and even with curative resection, they remain at a high risk of relapse and mortality. Thus, there is a great need for effective adjuvant therapy for patients with gastric carcinoma. Our previous clinic studies suggested that Chinese herbal recipe Shenfuweikang have therapeutic effects on gastric pre-malignant lesion, with increasing the reversal of the atrophic gastritis, decreasing the recurrence and improving the life quality $[1,2]$. The Shenfuweikang decoction consists of Codonopsis pilosula (Franch) Nannf., Poria cocos (Schw.) Wolf, Atractylodes macrocephala koidz, Glycyrrhiza uralensis Fisch, which were verfied to inhibit the proliferation of dysplasia of the atrophic gastritis [3]. Because of its lower toxic side-effect compared with chemical therapy, it is worth to make a further research on its anti-cancer mechanism.

Similar to the other malignant tumors, gastric carcinoma is always accompanying with abnormal cell proliferation and differentiation, as well as with abnormal apoptosis $[7,8]$. The enhanced induction of apoptosis in human gastric carcinoma cells can be observed after treatment with 5-Fluorouracil, Cisplatin, arsenous oxide and so on $[9,10]$. These data suggest that inducing cancer cell apoptosis should be a therapeutic method for gastric carcinoma. The present study indicated that tumor growth was significantly inhibited by treatment with the Shenfuweikang decoction. TUNEL method and cytometry analysis clarified that Shenfuweikang decoction could enhance apoptosis. The results suggest that the mechanism of the inhibition of gastric cancer cells in vivo by Shenfuweikang herbs is related with inducing apoptosis.

In the present study, we found that after treated with Shenfuweikang herbs, the growth of tumor was inhibited compared with the control group. We presumed that the herbs could activate the immune cells to attack the tumor cells as well as induce the apoptosis of the tumor cells directly $[11,12]$. The results showed that Shenfuweikang herbs could activate the immune cells to secret cytokines, IFN- $\gamma$ and granzyme B, which are able to induce the apoptosis and necrosis of tumor cells. We also found that splenocytes were activated and elicited the difinite cytotoxic effects on tumor cells, which were likely to secret cytokines, such as IFN- $\gamma$ and granzyme B to exert their immune effects. It has been verified that specific immune cells could induce the apoptosis of tumor cells [13]. Apoptosis is a complex, tightly regulated, and active cellular process by which individual cells are triggered to undergo programmed cell death, and simultaneously will not injury neighboring cells or elicit any inflammatory reactions $[13,14]$. Various triggering factor initiate corresponding proteo-lysis cascade reaction depending on mitochondrion or APO-1/FAS/CD95 receptor mediate apoptotic pathways [14]. There are many oncogenes and tumor suppressor gene products in the regulation and execution of apoptosis. The results suggest that the mechanism of the inhibition of gastric cancer cells in vivo by Shenfouweikang herbs is related with activating immune cells and further inducing apoptosis.

\section{Conclusions}

Shenfuweikang herbs inhibited gastric cancer cell growth. The anti-tumor effect of Shenfuweikang herbs lies in activating specific immune cells to secret certain cytokines, such as IFN- $\gamma$ and granzyme B to inhibit and kill tumor cells. The detailed molecular mechanism of Shenfuweikang herbs inhibiting gastric cancer cells still needs further investigation. 


\section{Acknowledgements}

This work is supported by Scientific Research Program Funded by Shaanxi University of Chinese Medicine and Shaanxi Provincial Education Department (No.2007JK233, 2009xj02, 2010JK484, 14JS025), the Scientific Research Program of Shaanxi Administration of Traditional Chinese Medicine (No.15-SCJH001), and the Natural Science Basic Research Plan in Shaanxi Province of China ((No.2016JM8023, 2016JM8150).

\section{References}

[1] H.P. Lin, S.C. Li, Protective effects of shenfuweikang on acute gastric mucous injury on rat, Shaanxi Journal of Traditional Chinese Medicine, 28 (2007) 1422-1423, in Chinese.

[2] S.C. Li, F. Wang, H.P. Lin, X.Y. Zhou, Effects of shenfuweikang on the secretion of serum gastrin and motilin in chronic atrophic gastritis, Jiangxi Journal of Traditional Chinese Medicine. 38 (2007) 68-69, in Chinese.

[3] H.P. Lin, X.P. Wang, Q. Fu, S.C. Li, Reverse effects of Chinese drug shenfuweikang herbs on chronic atrophic gastritis in rats, Modern Oncol. 20 (2012) 266-269, in Chinese.

[4] H.J. Ahn, D.S. Lee, Helicobacter pylori in gastric carcinogenesis, World J. Gastrointest Oncol. 7 (2015) 455-465.

[5] K. Sugano, Screening of gastric cancer in Asia, Best Pract. Res. Clin. Gastroenterol. 29 (2015) 895-905.

[6] K.S. Liu, I.O. Wong, W.K. Leung, Helicobacter pylori associated gastric intestinal metaplasia: Treatment and surveillance, World J. Gastroenterol. 22 (2016) 1311-1320.

[7] T. Matsunaga, Y. Tsuji, K. Kaai, et al, Toxicity against gastric cancer cells by combined treatment with 5-fluorouracil and mitomycin c: implication in oxidative stress, Cancer Chemother. Pharmacol. 66 (2010) 517-526.

[8] L. Qiao, B.C. Wong, Targeting apoptosis as an approach for gastrointestinal cancer therapy, Drug Resist. Updat. 12 (2009) 55-64.

[9] A.G. Zhao, H.L. Zhao, X.J. Jin, et al, Effects of Chinese Jianpi herbs on cell apoptosis and related gene expression in human gastric cancer grafted onto nude mice, World J. Gastroenterol. 8 (2002) 792-796.

[10] G.Z. Sun, Z.K. Wu, J.Y. Lu, W.P. Lu, X. Wang, The molecular mechanisms of Yang Wei Kang Liu powder on anticancer and reducing chemotherapy side-effect in combination with chemotherapy, Chinese-German Journal of Clinical Oncology. 9 (2010) 287-291.

[11] L. Saragoni, Upgrading the definition of early gastric cancer: better staging means more appropriate treatment, Cancer Biol. Med. 12 (2015) 355-361.

[12] J. Li, G.Z. Sun, H.S. Lin, Y.X. Pei, X. Qi, C. An, The herb medicine formula Yang Wei Kang Liu improves the survival of late stage gastric cancer patients and induces the apoptosis of human gastric cancer cell line through Fas/Fas ligand and Bax/Bcl-2 pathways, Int. Immunopharmacol. 8 (2008) 1196-1206. 
[13] A. Ashkenazi, V.M. Dixit, Death Receptors: Signaling and Modul ation, Science. 281 (1998) 1305-1308.

[14] M. Muller, S. Wilder, D. Bannasch, D. Israeli, K. Lehlbach, L.W. Min, p53 activates the CD95 (APO-1/Fas) gene in response to DNA damage by anticancer drugs, J. Exp. Med. 188 (1998) 2033-2045. 